\title{
Early re-laparotomy for patients with high-grade liver injury after damage-control surgery and perihepatic packing
}

\author{
Byung Hee Kang ${ }^{1} \cdot$ Kyoungwon Jung $^{1} \cdot$ Donghwan Choi ${ }^{1} \cdot$ Junsik Kwon ${ }^{1}$ (D)
}

Received: 18 June 2020 / Accepted: 18 September 2020 / Published online: 10 November 2020

(c) Springer Nature Singapore Pte Ltd. 2020

\begin{abstract}
Purpose The likelihood of re-bleeding after damage-control surgery (DCS) and perihepatic packing for high-grade liver injuries is a major concern. Thus, although early re-laparotomy tends to be recommended, we conducted this study to evaluate the feasibility of performing definite laparotomy within $\leq 48 \mathrm{~h}$ in this clinical population.

Methods The subjects of this retrospective study were 65 patients ( $n=24, \leq 48$-h group; $n=41,>48$-h group) who underwent DCS and perihepatic packing. The primary outcome was the rate of repacking for bleeding during re-laparotomy and the secondary outcomes were mortality and length of stay in the intensive care unit (ICU).

Results The $\leq 48$-h group had a higher rate of angioembolization and transfusion of red blood cells (RBCs), fresh frozen plasma, and platelets, but the rates of repacking and mortality were not significantly different between the groups. However, the incidence of pneumonia and ventilation support requirement were significantly lower in the $\leq 48$-h group than in the $>$ 48-h group.

Conclusion The re-laparotomy performed within $\leq 48 \mathrm{~h}$ after DCS and perihepatic packing is feasible for patients with high grade liver injury, using angioembolization and aggressive transfusion, as required. Early re-laparotomy reduces the need for prolonged ventilator support and the incidence of ventilator-associated pneumonia.
\end{abstract}

Keywords Liver $\cdot$ Trauma $\cdot$ Laparotomy

\section{Introduction}

Damage-control surgery (DCS) is used widely in the management of trauma patients. For patients with abdominal trauma, DCS is used in the intensive care unit (ICU), without initial surgery, to control hemorrhage and contamination, followed by intraperitoneal packing and rapid closure, which allows for resuscitation and subsequent definitive laparotomy [1]. As these patients are at high risk of abdominal

Junsik Kwon

aquaestel@gmail.com

Byung Hee Kang

kbhname@gmail.com

Kyoungwon Jung

jake98@daum.net

Donghwan Choi

claptonc@naver.com

1 Department of Trauma Surgery, Ajou School of Medicine, 164 Worldcup-ro, Yeongtong-gu, Suwon, Gyeonggi-do 16499, Republic of Korea compartment syndrome [2], the abdominal fascia is generally not approximated during closure [3]. The indications for DCS have been extended beyond intraperitoneal packing to include vascular and gastrointestinal injuries, mesenteric ischemia, and gross contamination [4]. It is generally recommended that re-laparotomy, and any other surgery required, be performed within 24-48 $\mathrm{h}$ after the index DCS [5], as delayed re-laparotomy increases the risk of infection and failure of definite fascial closure [6-8]. However, extending the timeline for re-laparotomy beyond $48 \mathrm{~h}$ has recently been recommended for patients with high-grade liver injury requiring perihepatic packing to prevent re-bleeding, $[9,10]$. This recommendation does not consider the new management strategies for traumatic coagulopathy that have been developed, including massive transfusion protocol, diagnostic criteria, medication support, and ratio-driven resuscitation, to maintain the adequate ratio between red blood cells (RBCs), plasma, and platelets [11-13]. Strategies for the management of high-grade liver trauma have also been developed, with angioembolization used to decrease the risk of bleeding and mortality [14, 15]. Considering 
these new trauma management strategies, we hypothesized that planned re-laparotomy within $\leq 48 \mathrm{~h}$ after perihepatic packing could be feasible. Therefore, the aim of this study was to evaluate the feasibility of performing re-laparotomy within $\leq 48 \mathrm{~h}$ after perihepatic packing for patients with high-grade liver injury. The primary outcome was the rate of repacking for bleeding at the time of re-laparotomy, with secondary outcomes being mortality, length of stay (LOS) in the ICU, and complications.

\section{Methods}

\section{Patients}

Patients who underwent DCS and perihepatic packing in our trauma center between January, 2011 and December, 2019 , were included in this study. The exclusion criteria were as follows: age $<18$ years, death before re-laparotomy, and unplanned re-laparotomy because of bleeding. Resuscitation was performed according to the Advanced Trauma Life Support guideline, which includes indications for laparotomy [16]. During laparotomy, selective ligation of bleeding sources in the liver was performed, if possible. For persistent bleeding, liver suturing was usually performed in conjunction with a Pringle manoeuvre, applied for $<30 \mathrm{~min}$. Non-anatomical liver resection was performed if suturing was not adequate to restore liver viability. Approximately 5-6 laparotomy gauzes were used for perihepatic packing, and an open abdomen was created using the vacuum pack method. Patients were transferred to the ICU for correction of the lethal triad (acidosis, hypothermia, and coagulopathy), with re-laparotomy performed after the correction of coagulopathy.

The motivation for our study was the building of our new trauma center in 2016, since when, we have performed more aggressive transfusion and angioembolization for the correction of coagulopathy [17]. However, angioembolization is not performed routinely after DCS, with the decision being made by individual surgeons. Although re-laparotomy can be performed earlier in our new trauma center with the advanced trauma procedures available, a consistent change in our protocol was not made then, with treatment strategies decided by individual surgeons. Therefore, we dichotomized patients into those who underwent re-laparotomy within $\leq 48$ or $>48 \mathrm{~h}$ after perihepatic packing and compared injury characteristics, treatment, and clinical outcomes between the two groups.

\section{Definitions}

Liver injury was graded according to the liver injury scale of the American Association of Surgery in Trauma [18]. Liver resection included any non-anatomical resection, such as wedge resection. Angioembolization included any attempt at angiography, even in the absence of definite arterial bleeding; angioembolization after re-laparotomy was excluded. Repacking was defined as packing performed at the time of the first re-laparotomy for bleeding. Complications related to liver injury, such as biloma, were identified on abdominal computed tomography and required drainage. Pneumonia was defined as ventilator-associated pneumonia after the first period of intubation, as defined by the criteria of the National Healthcare Safety Network definition of ventilatorassociated pneumonia (PNU2) [19].

\section{Statistical analysis}

After evaluating the normality of distribution of the data using the Kolmogorov-Smirnov test, continuous variables were compared between the two groups using Student's t-test (mean \pm standard deviation) or the Mann-Whitney $U$ test (median value and interquartile range), as appropriate, whereas categorical variables were compared using the chisquared test. All analyses were performed using SPSS version 23.0 (IBM, Chicago, IL, USA).

\section{Results}

\section{Patients' characteristics}

Of the 133 patients who underwent perihepatic packing during the study period, 55 died before re-laparotomy (mortality rate, $41.4 \%$ ) and 16 did not meet the inclusion criteria. Accordingly, 67 patients ( 24 in the $\leq 48$-h group and 41 in the $>48$-h group) were included in our analysis (Fig. 1). The initial clinical data (Table 1) and injury severity (Table 2) did not differ significantly between the two groups.

\section{Bleeding control for liver injury}

The operative times were similar in the two groups; however, the rate of angioembolization and blood transfusion during the $24 \mathrm{~h}$ post-surgery was greater in the $\leq 48$-h group than in the $>48$-h group (Table 3 ). Three of the eight patients in the $\leq 48$-h group had no definite bleeding during angioembolization as empirical gel foam had been applied, whereas two patients in the $>48$-h group had definite bleeding. The international normalized ratio (INR) and lactate level during re-laparotomy were higher in the $\leq 48$-h group than in the $>48$-h group, although these levels were within normal ranges. 
Fig. 1 Patient flowchart

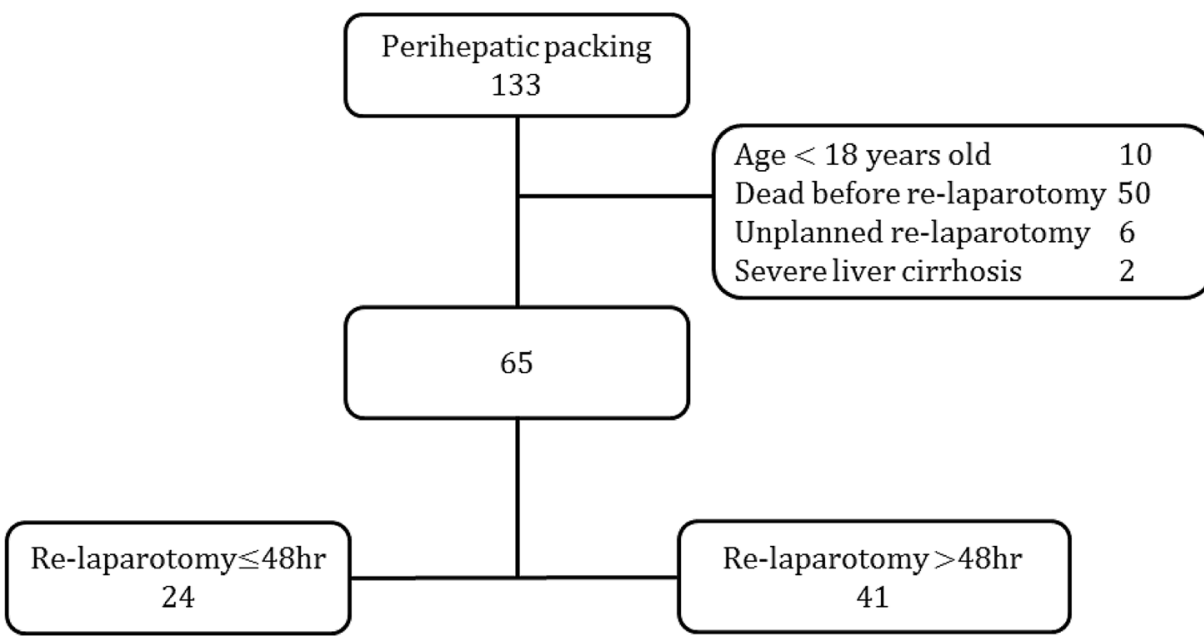

Table 1 Clinical characteristics of the patients in this study

\begin{tabular}{llll}
\hline & Packing $\leq 48 \mathrm{~h}(n=24)$ & Packing $>48 \mathrm{~h}(n=41)$ & $p$ \\
\hline Sex (male:female) & $18: 6$ & $33: 8$ & 0.603 \\
Age (years) & $48.0 \pm 15.6$ & $45.4 \pm 13.4$ & 0.474 \\
Injury mechanism (blunt, \%) & $23(95.8 \%)$ & $37(61.7 \%)$ & 0.644 \\
Systolic BP (mmHg) & $97.3 \pm 22.6$ & $107.8 \pm 32.4$ & 0.165 \\
Pulse (/min) & $109.9 \pm 26.7$ & $98.3 \pm 22.1$ & 0.065 \\
Glasgow coma score & $10.7 \pm 3.9$ & $11.6 \pm 4.1$ & 0.398 \\
\hline
\end{tabular}

Table 2 Distribution of injuries

\begin{tabular}{llll}
\hline & Packing $\leq 48 \mathrm{~h}(n=24)$ & Packing $>48 \mathrm{~h}(n=41)$ & $p$ \\
\hline $\begin{array}{l}\text { Initial lactate (mmol/L) } \\
\text { Liver injury grade }\end{array}$ & $4.75[3.63-7.18]$ & $5.23[3.24-6.49]$ & 0.791 \\
III & $1(4.2 \%)$ & $9(22.0 \%)$ & 0.157 \\
IV & $17(70.8 \%)$ & $23(56.1 \%)$ & \\
V & $6(25.0 \%)$ & $9(22.0 \%)$ & \\
Injury severity score & $34[27-37]$ & $26[22-41]$ & 0.390 \\
Abbreviated injury scale & & & \\
Head & $4[4-4]$ & $3[2-5]$ & 0.435 \\
Face and neck & $2[2-2]$ & $2[2-2]$ & 1.000 \\
Chest & $3[3-3]$ & $3[3-4]$ & 0.284 \\
Abdomen & $4[4-5]$ & $4[4-4]$ & 0.128 \\
Extremity & $3[2-3]$ & $2[2-3]$ & 0.561 \\
\hline
\end{tabular}

\section{Clinical outcomes}

There were no significant differences in the rate of repacking, mortality, and LOS in the ICU between the two groups. However, the total duration of ventilator support as well as the number of days on ventilator support after re-laparotomy were significantly lower in the $\leq 48$-h group than in the $>48$-h group. The incidence of ventilator-associated pneumonia was also lower in the $\leq 48$-h group than in the $>48$-h group, but the rate of sepsis was not different between the two groups (Table 4).

\section{Discussion}

High-grade liver injury is the leading cause of death of patients with abdominal trauma and is associated with a high mortality rate $[10,18]$. In these patients, uncontrolled bleeding is associated with an increased risk of early (within $24 \mathrm{~h}$ ) 
Table 3 Procedures performed to control bleeding

\begin{tabular}{lllr}
\hline & Packing $\leq 48 \mathrm{~h}(n=24)$ & Packing $>48 \mathrm{~h}(n=41)$ & \multicolumn{1}{c}{$p$} \\
\hline Duration of packing (h) & $28.9 \pm 9.2$ & $71.3 \pm 17.5$ & $<\mathbf{0 . 0 0 1}$ \\
Operation time (min) & $80.5 \pm 47.5$ & $102.1 \pm 51.7$ & 0.098 \\
Liver suture $(n, \%)$ & $18(75.0 \%)$ & $37(90.2 \%)$ & 0.154 \\
Liver resection $(n, \%)$ & $3(12.5 \%)$ & $3(7.3 \%)$ & 0.662 \\
Angio-embolization $(n, \%)$ & $8(33.3 \%)$ & $2(4.9 \%)$ & $\mathbf{0 . 0 0 4}$ \\
Transfusion during 24 h & & & \\
$\quad$ Red blood cells (units) & $20[10-26]$ & $7[6-18]$ & $\mathbf{0 . 0 0 1}$ \\
Fresh frozen plasma (units) & $18[12-29]$ & $11[7-14]$ & $\mathbf{0 . 0 0 2}$ \\
Platelets (units) & $14[8-24]$ & $8[0-16]$ & $\mathbf{0 . 0 3 3}$ \\
At second operation & & & \\
INR & $1.36[1.27-1.46]$ & $1.21[1.13-1.32]$ & $\mathbf{0 . 0 0 2}$ \\
Lactate (mmol/L) & $2.55[1.74-4.45]$ & $1.29[0.93-2.24]$ & $\mathbf{0 . 0 0 2}$ \\
\hline
\end{tabular}

Bold values indicate $p<0.05$

Table 4 Clinical outcomes

\begin{tabular}{lccr}
\hline & $\begin{array}{l}\text { Pack- } \\
\text { ing } \leq 48 \mathrm{~h} \\
(n=24)\end{array}$ & $\begin{array}{l}\text { Packing }>48 \mathrm{~h} \\
(n=41)\end{array}$ & $p$ \\
\hline Repacking $(n, \%)$ & $3(12.5 \%)$ & $3(7.3 \%)$ & 0.662 \\
Mortality (n, \%) & $4(16.7 \%)$ & $6(14.6 \%)$ & 0.827 \\
ICU LOS (days) & $9[5-31]$ & $18[11-28]$ & 0.077 \\
Ventilation day (days) & & & \\
Total & $3[3-7]$ & $10[7-19]$ & $<\mathbf{0 . 0 0 1}$ \\
After re-laparotomy & $2[2-6]$ & $9[5-16]$ & $\mathbf{0 . 0 0 2}$ \\
Complications $(n, \%)$ & & & 0.348 \\
Sepsis & $4(16.7 \%)$ & $11(26.8 \%)$ & $\mathbf{0 . 0 2 5}$ \\
Pneumonia & $4(16.7 \%)$ & $18(43.9 \%)$ & 0.204 \\
Drain for fluid col- & $7(29.2 \%)$ & $6(14.6 \%)$ & 0.715 \\
lection & & & 0.549 \\
Fascia dehiscence & $4(16.7 \%)$ & $5(12.2 \%)$ & 0.400 \\
Liver abscess & $2(8.3 \%)$ & $1(2.4 \%)$ & 0.133 \\
Liver infarction & $1(4.2 \%)$ & $5(12.2 \%)$ & \\
Biloma & $2(8.3 \%)$ & $0(0.0 \%)$ & \\
\hline
\end{tabular}

Bold values indicate $p<0.05$

${ }^{a}$ Length of stay in intensive care unit

and perioperative death $[14,20]$. Our overall mortality rate was $41.4 \%$, with $81.8 \%$ of these deaths occurring before relaparotomy after DCS. Since Rotondo et al. introduced DCS, packing has become a widely accepted technique to control bleeding, with early re-laparotomy recommended after DCS $[1,5]$. Pommerening et al. reported that delayed re-laparotomy was associated with failure of fascia closure and thus recommended that re-laparotomy be performed within $24 \mathrm{~h}$, if possible, and not later than $48 \mathrm{~h}$ after DCS [7]. Abikhaled et al. suggested that packing be removed within $72 \mathrm{~h}$ of DCS, with a longer duration of packing being left increasing the risk of abscess formation and death [21]. In contrast, Nicol et al. indicated that although re-laparotomy should be performed within $48 \mathrm{~h}$ after packing, a prolonged duration of leaving packing in did not increase the incidence of septic complication [9]. The incidence of re-bleeding after perihepatic packing for high-grade liver injury is a principal concern and thus re-laparotomy is usually performed $>48 \mathrm{~h}$ after perihepatic packing $[10,22,23]$. However, the study by Nicol et al. was published more than a decade ago when angioembolization could not be performed until the first relaparotomy [9].

The management of hepatic trauma is changing, and more non-operative strategies are being used for severe liver injury. For example, angiography with embolization can now be used to control bleeding and stabilize patients, with better outcomes [24]. In fact, Suen et al. found that hepatic angioembolization decreased the mortality rate caused by liver injury [15]. Angioembolization is now considered an important component for the control of bleeding in trauma patients, with a multidisciplinary approach after DCS improving clinical outcomes of patients with high-grade liver injury $[25,26]$. We identified a higher rate of angioembolization among patients who underwent re-laparotomy within $\leq 48 \mathrm{~h}$ after perihepatic packing in the present study; however, a lack of precise indications for angioembolization after DCS being performed at the discretion of individual surgeons existed. Moreover, the amount of blood transfusion in patients with embolization was not significantly different. Future research is warranted to define the criteria for postDCS angioembolization.

After DCS, the patient must be managed in the ICU to control and reverse the lethal triad of hypothermia, acidosis, and coagulopathy. To correct coagulopathy, fresh frozen plasma (FFP) and platelets are administered. Glaser et al. demonstrated that ratio-driven resuscitation in combat casualties was an independent predictor of early fascial closure after laparotomy [27], with the administration of FFP required to maintain the recommended 
1:1:1 RBC:FFP:platelet ratio, based on the randomized PROPPR trial [11]. In this study, the rates of FFP and platelet administration rates were not remarkably lower than those of RBC administration in the two groups. The large volume of RBC transfusion given within $24 \mathrm{~h}$ may be attributed to an improved logistic process, such as active use of the blood refrigerator placed in the $\mathrm{T}$ bay, but the results of the study cannot be confirmed.

As leaving the packing in situ for too long may be related to sepsis, early removal of perihepatic packing has been recommended $[5,21,28]$. However, the study by Nicol et al. showed that delaying the removal of perihepatic packing did not increase the rate of infection [9]; our findings were consistent with theirs. Conversely, the duration of ventilator support required was shorter and the incidence of ventilator-associated pneumonia was lower in the $\leq 48$-h group than in the $>48$-h group. Furthermore, not only the duration of packing but also ICU management may be an important factor influencing clinical outcomes. Spontaneous awakening and breathing reduced the length of ventilator support and the incidence of pneumonia, with an open abdomen not being an obstacle to extubation [29, 30]. Based on the current evidence, we have now amended our ICU management protocol to include the use of light sedation and early awakening, which could decrease the LOS in the ICU and duration of ventilator support needed. However, light sedation was not utilized for patients treated with an open abdomen after DCS, being given only after the definite fascia closure. As deep sedation influences the incidence of pneumonia and ventilator support, its use before re-laparotomy might affect measured clinical outcomes. Furthermore, in our study, the duration of ventilation support in the $\leq 48$-h group was reduced by 7 days, which was greater than the 3 days reported in a spontaneous awakening and breathing trial [31].

Our study has several limitations. First, its retrospective design limits assessment of causality and potentially creates selection bias. Second, although an increased use of angioembolization, transfusion, and improved ICU management was possible after the establishment of our new trauma center, the precise indications or timing of re-laparotomy did not change definitively, with some patients undergoing re-laparotomy $>48 \mathrm{~h}$ after DCS and perihepatic packing and angioembolization being performed inconsistently. Therefore, the performance of surgical procedures that could aid in lowering the risk of rebleeding was limited. Third, the number of patients in our study sample was small, which limited the interpretation of results. However, it reflects the overall low incidence of high-grade liver injury and the associated high mortality rate. Fourth, the surgeons in our new trauma center have varying years of experience and include some who are young and inexperienced; therefore, surgeries performed by different surgeons to control bleeding may have influenced outcomes, owing to individual expertise level.

In conclusion, our study demonstrated that re-laparotomy performed within $\leq 48 \mathrm{~h}$ after DCS and perihepatic packing is feasible in patients with high-grade liver injury, using a multidisciplinary approach, which includes angioembolization and aggressive transfusion, as required. Early relaparotomy reduced the length of ventilator support and the incidence of ventilator-associated pneumonia.

\section{References}

1. Rotondo MF, Schwab CW, McGonigal MD, Phillips GR 3rd, Fruchterman TM, Kauder DR, et al. "Damage control": an approach for improved survival in exsanguinating penetrating abdominal injury. J Trauma. 1993;35(3):375-82 (discussion 82-3).

2. Raeburn CD, Moore EE, Biffl WL, Johnson JL, Meldrum DR, Offner PJ, et al. The abdominal compartment syndrome is a morbid complication of post-injury damage control surgery. Am J Surg. 2001;182(6):542-6.

3. Regner JL, Kobayashi L, Coimbra R. Surgical strategies for management of the open abdomen. World J Surg. 2012;36(3):497510. https://doi.org/10.1007/s00268-011-1203-7.

4. Chiara O, Cimbanassi S, Biffl W, Leppaniemi A, Henry S, Scalea $\mathrm{TM}$, et al. International consensus conference on open abdomen in trauma. J Trauma Acute Care Surg. 2016;80(1):173-83. https ://doi.org/10.1097/TA.0000000000000882.

5. Coccolini F, Roberts D, Ansaloni L, Ivatury R, Gamberini E, Kluger Y, et al. The open abdomen in trauma and nontrauma patients: WSES guidelines. World J Emerg Surg WJES. 2018;13:7. https://doi.org/10.1186/s13017-018-0167-4.

6. Lambertz A, Mihatsch C, Roth A, Kalverkamp S, Eickhoff R, Neumann UP, et al. Fascial closure after open abdomen: initial indication and early revisions are decisive factors-a retrospective cohort study. Int J Surg. 2015;13:12-6. https://doi.org/10.1016/j. ijsu.2014.11.025.

7. Pommerening MJ, DuBose JJ, Zielinski MD, Phelan HA, Scalea TM, Inaba K, et al. Time to first take-back operation predicts successful primary fascial closure in patients undergoing damage control laparotomy. Surgery. 2014;156(2):431-8. https://doi. org/10.1016/j.surg.2014.04.019.

8. Hatch QM, Osterhout LM, Podbielski J, Kozar RA, Wade CE, Holcomb JB, et al. Impact of closure at the first take back: complication burden and potential overutilization of damage control laparotomy. J Trauma. 2011;71(6):1503-11. https://doi.org/10.1097/ TA.0b013e31823cd78d.

9. Nicol AJ, Hommes M, Primrose R, Navsaria PH, Krige JE. Packing for control of hemorrhage in major liver trauma. World J Surg. 2007;31(3):569-74. https://doi.org/10.1007/s00268-006-0070-0.

10. Doklestic K, Stefanovic B, Gregoric P, Ivancevic N, Loncar Z, Jovanovic B, et al. Surgical management of AAST grades III-V hepatic trauma by Damage control surgery with perihepatic packing and Definitive hepatic repair-single centre experience. World J Emerg Surg WJES. 2015;10:34. https://doi.org/10.1186/s1301 7-015-0031-8.

11. Holcomb JB, Tilley BC, Baraniuk S, Fox EE, Wade CE, Podbielski JM, et al. Transfusion of plasma, platelets, and red blood cells in a 1:1:1 vs a 1:1:2 ratio and mortality in patients with severe trauma: the PROPPR randomized clinical trial. JAMA. 2015;313(5):471-82. https://doi.org/10.1001/jama.2015.12. 
12. Spahn DR, Bouillon B, Cerny V, Duranteau J, Filipescu D, Hunt $\mathrm{BJ}$, et al. The European guideline on management of major bleeding and coagulopathy following trauma: fifth edition. Crit Care. 2019;23(1):98. https://doi.org/10.1186/s13054-019-2347-3.

13. Cohen MJ, Christie SA. Coagulopathy of trauma. Crit Care Clin. 2017;33(1):101-18. https://doi.org/10.1016/j.ccc.2016.08.003.

14. Peitzman AB, Richardson JD. Surgical treatment of injuries to the solid abdominal organs: a 50-year perspective from the Journal of Trauma. J Trauma. 2010;69(5):1011-21. https://doi.org/10.1097/ TA.0b013e3181f9c216.

15. Suen K, Skandarajah AR, Knowles B, Judson R, Thomson BN. Changes in the management of liver trauma leading to reduced mortality: 15-year experience in a major trauma centre. ANZ J Surg. 2016;86(11):894-9. https://doi.org/10.1111/ans.13248.

16. ATLS Subcommittee, American College of Surgeons, Committee on Trauma, International ATLS Working Group. Advanced trauma life support (ATLS(R)): the ninth edition. J Trauma Acute Care Surg. 2013;74(5):1363-6. https://doi.org/10.1097/TA.0b013 e31828b82f5.

17. Kang BH, Choi D, Cho J, Kwon J, Huh Y, Moon J, et al. Efficacy of uncross-matched type o packed red blood cell transfusion to traumatic shock patients: a propensity score match study. J Korean Med Sci. 2017;32(12):2058-63. https://doi.org/10.3346/ jkms.2017.32.12.2058.

18. Moore EE, Cogbill TH, Jurkovich GJ, Shackford SR, Malangoni MA, Champion HR. Organ injury scaling: spleen and liver (1994 revision). J Trauma. 1995;38(3):323-4. https://doi. org/10.1097/00005373-199503000-00001.

19. Spalding MC, Cripps MW, Minshall CT. Ventilator-associated pneumonia: new definitions. Crit Care Clin. 2017;33(2):277-92. https://doi.org/10.1016/j.ccc.2016.12.009.

20. Piper GL, Peitzman AB. Current management of hepatic trauma. Surg Clin N Am. 2010;90(4):775-85. https://doi.org/10.1016/j. suc.2010.04.009.

21. Abikhaled JA, Granchi TS, Wall MJ, Hirshberg A, Mattox KL. Prolonged abdominal packing for trauma is associated with increased morbidity and mortality. Am Surg. 1997;63(12):110912 (discussion 12-3).

22. Di Saverio S, Catena F, Filicori F, Ansaloni L, Coccolini F, Keutgen XM, et al. Predictive factors of morbidity and mortality in grade IV and V liver trauma undergoing perihepatic packing: single institution 14 years experience at European trauma centre. Injury. 2012;43(9):1347-54. https://doi.org/10.1016/j.injur y.2012.01.003.

23. Prichayudh S, Sirinawin C, Sriussadaporn S, Pak-art R, Kritayakirana K, Samorn P, et al. Management of liver injuries: predictors for the need of operation and damage control surgery. Injury. 2014;45(9):1373-7. https://doi.org/10.1016/j.injury.2014.02.013.

24. Melloul E, Denys A, Demartines N. Management of severe blunt hepatic injury in the era of computed tomography and transarterial embolization: a systematic review and critical appraisal of the literature. J Trauma Acute Care Surg. 2015;79(3):468-74. https:// doi.org/10.1097/TA.0000000000000724.

25. Asensio JA, Petrone P, Garcia-Nunez L, Kimbrell B, Kuncir E. Multidisciplinary approach for the management of complex hepatic injuries AAST-OIS grades IV-V: a prospective study. Scand J Surg. 2007;96(3):214-20. https://doi.org/10.1177/14574 9690709600306.

26. Baldoni F, Di Saverio S, Antonacci N, Coniglio C, Giugni A, Montanari N, et al. Refinement in the technique of perihepatic packing: a safe and effective surgical hemostasis and multidisciplinary approach can improve the outcome in severe liver trauma. Am J Surg. 2011;201(1):e5-14. https://doi.org/10.1016/j.amjsu rg.2010.05.015.

27. Glaser J, Vasquez M, Cardarelli C, Dunne J, Elster E, Hathaway $\mathrm{E}$, et al. Ratio-driven resuscitation predicts early fascial closure in the combat wounded. J Trauma Acute Care Surg. 2015;79(4 Suppl 2):S188-92. https://doi.org/10.1097/TA.0000000000000741.

28. Chabot E, Nirula R. Open abdomen critical care management principles: resuscitation, fluid balance, nutrition, and ventilator management. Trauma Surg Acute Care Open. 2017;2(1):e00063. https://doi.org/10.1136/tsaco-2016-000063.

29. Marra A, Ely EW, Pandharipande PP, Patel MB. The ABCDEF bundle in critical care. Crit Care Clin. 2017;33(2):225-43. https ://doi.org/10.1016/j.ccc.2016.12.005.

30. Sujka JA, Safcsak K, Cheatham ML, Ibrahim JA. Trauma patients with an open abdomen following damage control laparotomy can be extubated prior to abdominal closure. World J Surg. 2018;42(10):3210-4. https://doi.org/10.1007/s00268-018-4610-1.

31. Girard TD, Kress JP, Fuchs BD, Thomason JW, Schweickert WD, Pun BT, et al. Efficacy and safety of a paired sedation and ventilator weaning protocol for mechanically ventilated patients in intensive care (awakening and breathing controlled trial): a randomised controlled trial. Lancet. 2008;371(9607):126-34. https ://doi.org/10.1016/s0140-6736(08)60105-1.

Publisher's Note Springer Nature remains neutral with regard to jurisdictional claims in published maps and institutional affiliations. 